\title{
Minimum ages for pecked rock markings from Jinmium, north western Australia
}

\author{
ALAN WATCHMAN, PAUL TAÇON, RICHARD FULLAGAR AND LESLEY HEAD
}

\begin{abstract}
Sixteen accelerator mass spectrometry (AMS) radiocarbon (14C) determinations for oxalate crusts overlying three pecked rock markings (cupules) at three separate localities in the Keep River area of north western Australia provide age estimates from $1430-11,000$ years since the markings were last retouched. These are the first direct dates reported for rock-art of this kind. While these determinations do not lend strong support to previous arguments for a Pleistocene cupule age they also do not refute such arguments. We maintain the age of the crusts is more closely related to climatic fluctuations rather than when cupules were produced, with crust formation directly related to the nature of local ecological conditions. We discuss implications for estimating the time-depth of rock-art sequences in northern Australia, and general problems with the direct dating of rock-art.
\end{abstract}

\section{Introduction}

During the past decade there has been much interest and excitement in dating rock-art around the world as such age determinations can tell us about the antiquity of particular images, pictures, patterns, 'styles', sites and even cultures. The results of rock-art dating programs can also inform us about cultural change and perhaps even the origin of certain symbolic processes or 'art' itself. In northern Australia the antiquity of rock-art is of great significance in interpretations of regional, local and national prehistory. In several recent regional syntheses, the general sequence of rock-art places highly distinctive pecked cupules at the beginning (Chaloupka 1993; Flood 1996, 1997; Taçon et al. 1997; Taçon and Chippindale 1994; Walsh 1994; Welch 1993). This interpretation rests primarily on local evidence of superimpositioning of distinct rock-art styles.

In addition, a number of styles have been dated directly (eg. Nelson et al. 1995; Roberts et al. 1997; Watchman et al. 1997) giving time depth to chronologies and testing age assumptions based on indirect dating methods. However, direct dates have been challenged on various grounds, with no clear consensus on absolute ages

AW: School of Anthropology, Archaeology and Sociology, James Cook University, Townsville, Qld 4811; PT: Division of Anthropology, Australian Museum, 6-8 College St., Sydney NSW 2000; RF, LH: School of Geosciences, University of Wollongong, NSW 2522
(Bednarik 1996; Rosenfeld and Smith 1997; Taçon 1998). Research at Jinmium, in the Keep River area of the east Kimberley region, suggested ages for pecked cupules based on thermoluminescence (TL) estimates of between about 58,000 and 75,000 years (W1424, W1645) on sediments which buried fragments of engraved sandstone (Fullagar et al. 1996). These TL estimates were considered provisional, pending further results from determinations on sediments using radiocarbon and optically stimulated luminescence (OSL), and on the radiocarbon dating of oxalate accretions formed over engravings. The radiocarbon and OSL results suggest the sediments burying the engraved sandstone fragment are less than 3,000 years old, and that the entire deposit may be Holocene (Roberts et al. 1998; see also Spooner 1998). This large discrepancy is an extreme instance of the contradictory views of dates for Australian sites currently arrived at by different dating procedures. Conflicting opinions of the optical and thermoluminescence age estimates persist and the dating of initial human occupation at Jinmium is not yet resolved (Roberts 1998; Price 1998a, b).

Calcium oxalate salts that have formed in hard crusts on ledges within rockshelters across northern Australia have been used for determining the ages of rock paintings (Watchman 1993) and engravings (Watchman and Hatte 1996). Calcium oxalate, either as whewellite $\left(\mathrm{CaC}_{2} \mathrm{O}_{4} \cdot \mathrm{H}_{2} \mathrm{O}\right)$ or weddellite $\left(\mathrm{CaC}_{2} \mathrm{O}_{4} \cdot 2 \mathrm{H}_{2} \mathrm{O}\right)$, is believed to crystallise as a result of microorganic interactions (particularly fungi and algae) with dust and water on damp surfaces in rock shelters; once formed, it remains stable, without exchanging isotopes with atmospheric or other sources of carbon. It is that stability which gives confidence in radiocarbon age estimates on oxalate crusts. Stratified layers of oxalate in crusts that are more than 2 $\mathrm{mm}$ thick from north Queensland have been dated in chronological sequence from almost 30,000 to 3,000 years ago (Watchman and Campbell 1996). Radiocarbon dating the formation of oxalate at the base of a crust enables the estimation of minimum ages for the underlying cupules. We present here the results of the direct dating of such crusts overlying the cupules.

\section{Keep River Region cupules}

In 1996 and 1997 twenty-six cupule sites were recorded at Jinmium and Granilpi (Taçon et al. 1997). We define 


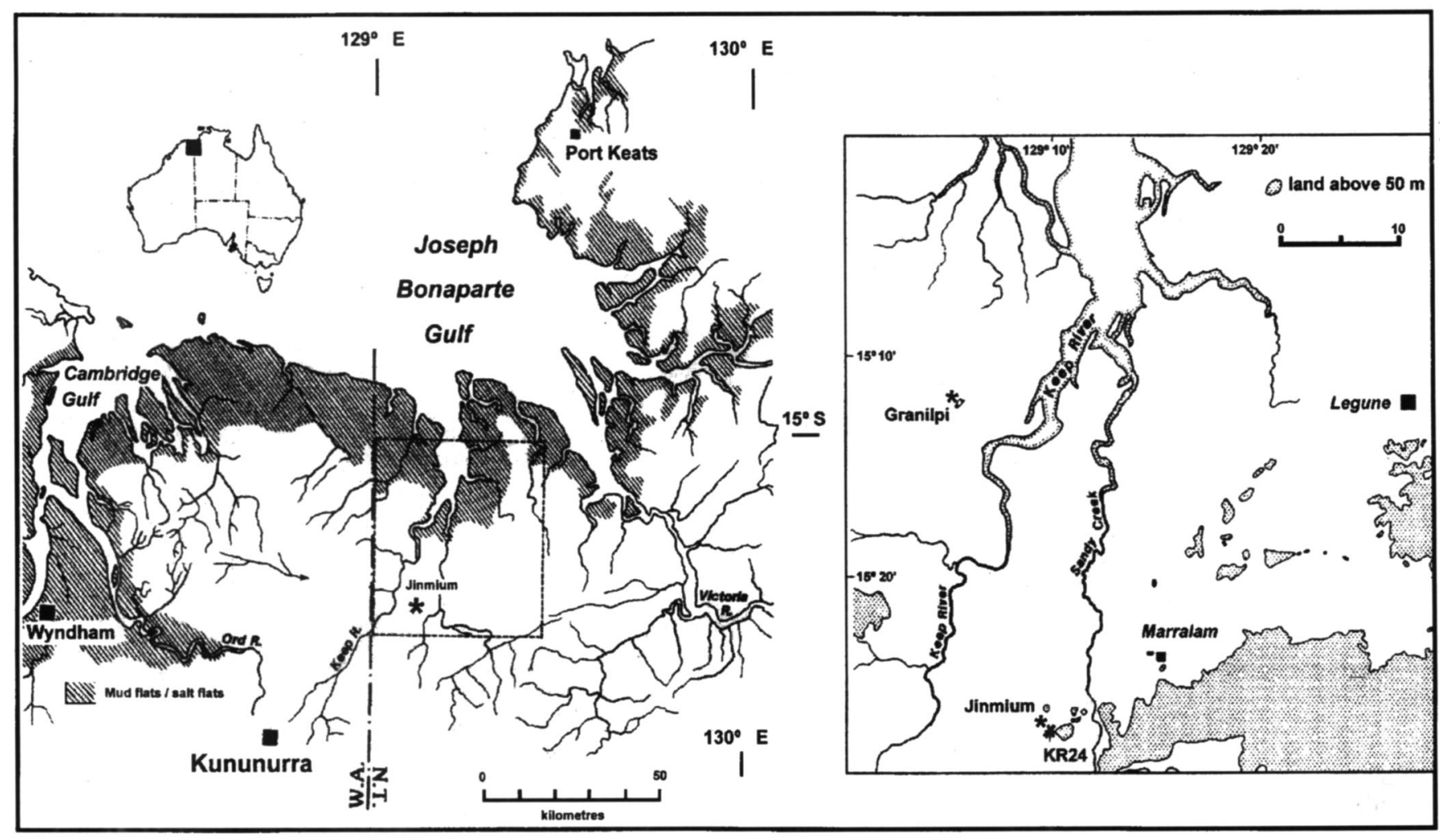

Figure 1. Map of the Western Australia-Northern Territory border region showing the locations of the Jinmium and Granilpi sites.

cupules as 'cup-shaped non-utilitarian marks' after Flood (1997:145-6) and note distinctions with grinding hollows that resulted from food or ochre processing. In brief, grinding hollows are rather larger and occur only on flat or nearly so surfaces; cupules are rather smaller and commonly occur on vertical surfaces. Cupules resulted from pecking and pounding, with both techniques used to make some motifs in conjunction with abrading. Cupules on walls average $28-32 \mathrm{~mm}$ in diameter, those on boulders 58-66 mm. Structured distribution patterns were noted, and ten ways in which they were used to mark places, define boundaries, link localities, highlight natural features and define spaces within shelters were outlined (Taçon et al. 1997:957). In June 1997 we sampled cupules at three locations: two from within the Jinmium complex of sites (KR1 and KR24) and one at Granilpi (KR10; see Figure 1).

At KR1, the site excavated by Fullagar et al. (1996; see also Taçon et al. 1997:951), an accretion was removed from a small cupule near the highest part of the back wall of this relatively open rock shelter, just below the junction with the sloping ceiling. The cupule is one of a dozen or so on this part of the wall above a section of sandstone bearing many more cupules. The cupule considered suitable for sampling is on the right hand side of a protruding piece of rock, the remnant of a more extensive surface which has fallen off. The cupule measures 28.2 $\mathrm{mm}$ wide by $10.5 \mathrm{~mm}$ high and is $3.8 \mathrm{~mm}$ deep. Six lay- ers of accretion were removed progressively from the cupule in a micro-excavation process (Figure 2, 3).

The second site, KR24, is located several hundred metres south of KR1, on the eastern side of the sandstone ridge. It is a relatively small outlier lying a few metres from the main sandstone massif (see Taçon et al. 1997:952-54). The mushroom-shaped outlier has cupules pecked into the vertical and sloping surfaces under a protective ceiling and roof. A sloping surface with two rows of small pecked cupules was selected for study, and an accretion from one of the upper cupules (fourth from the top) was excavated for dating. Three layers were excavated from the crust overlying the cupule and an off-art crust sample removed from the sloping upper ledge (Figure 4).

The KR 10 rock shelter at Granilpi (Taçon et al. 1997:956) is formed in a medium-grained feldspathic sandstone. It is a low rock shelter formed in an arch, slightly above the surrounding plain. Near the back wall is a horizontal ledge on which cupules, about $25 \mathrm{~mm}$ across and $14 \mathrm{~mm}$ deep, have been made. A thin, shiny brown accretion has formed over these cupules. The front edge of the ledge has been broken across one cupule and accretion was removed from one side at the base of the depression. This micro-excavation resulted in six powdered samples representing six levels from within the crust (Figure 6). An off-art sample of crust was chipped from the ledge adjacent to the cupule. 


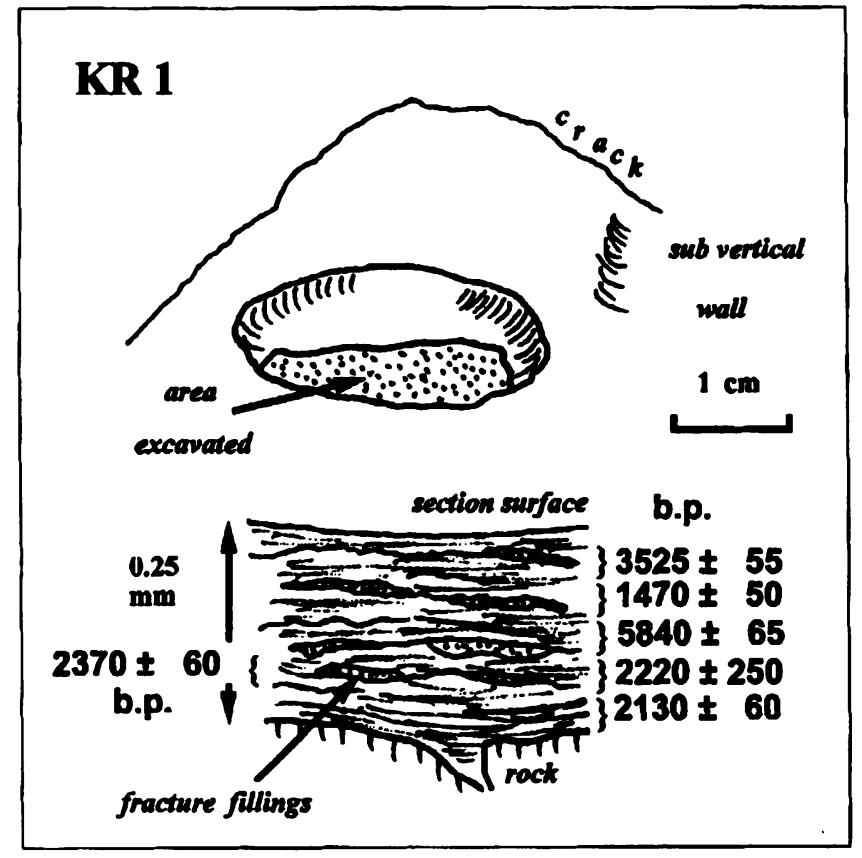

Figure 2. Sketches of the excavated area of crust and an enlarged cross section through the laminated crust at $\mathrm{KR} 1$ showing the radiocarbon age determinations for the respective excavated layers (years $\mathrm{bp}$ ). The single analysis on the left is from the dichromate extraction.

\section{Analytical methods}

Powders of crust were obtained by progressively removing layers of accretion approximately $0.05 \mathrm{~mm}$ thick from areas within cupules measuring roughly $2 \times 1 \mathrm{~cm}$. A small portable engraving tool fitted with a tungsten carbide dental burr and powered by two $6 \mathrm{~V}$ batteries was used for grinding the hard brown crusts. A binocular pair of magnifying glasses aided observations of the microexcavation process. The dusty powders were collected onto aluminium foil, labelled and stored in plastic film canisters. Fragments of crust were also removed from broken edges within cupules and on the surrounding rocks for micro-stratigraphic analyses.

Mineralogical and geochemical analyses were carried out on a sub-sample of each powder and a polished cross section of small rock surface chips were examined geochemically using a microprobe. For AMS ${ }^{14} \mathrm{C}$ dating, calcium oxalate salts were selected because they were found in the crusts and they have been used previously to determine the antiquity of engravings (Watchman and Hatte 1996), and the chronological succession of stratified layers of encrusted paintings (Watchman 1993; Watchman and Campbell 1996). The aim of dating carbon in oxalate salts by distinguishing micro-excavated layers in each crust is to establish if the age estimates are reliable. A single date or suite of dates on an entire crust would give a blurred average; a series from the microlayers should show a patterning. Conformable age

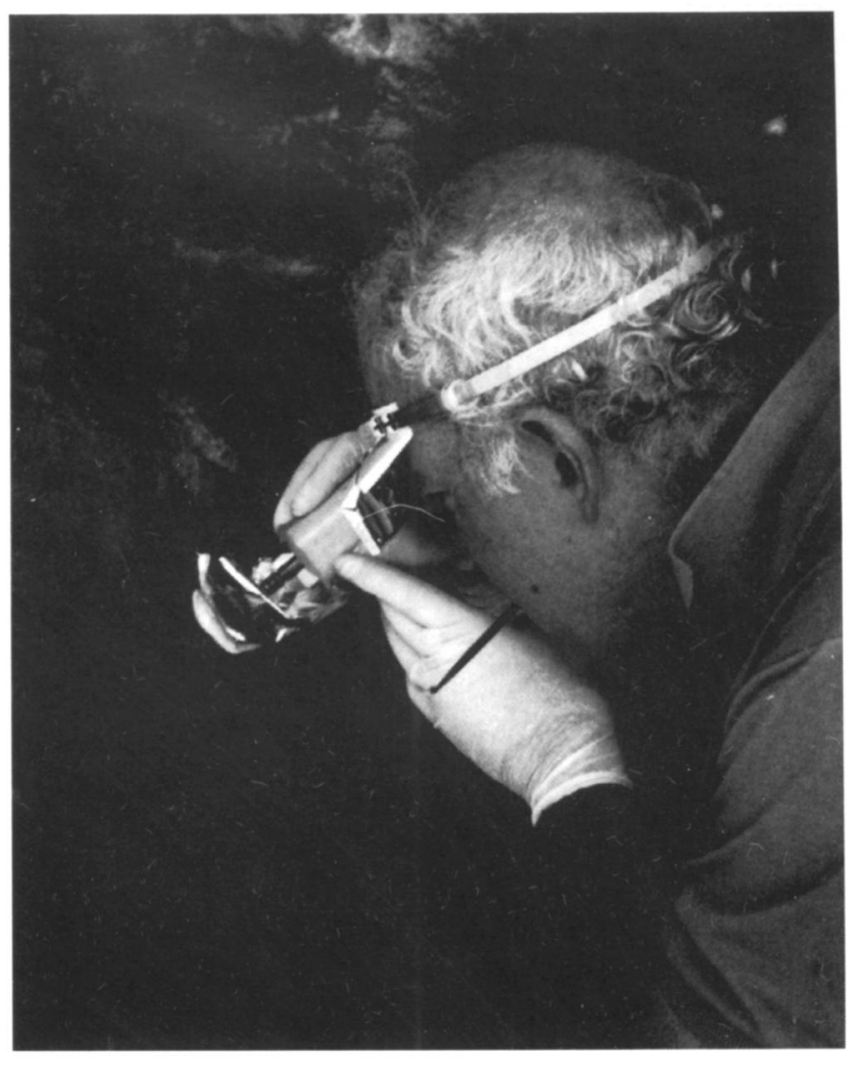

Figure 3. Detail of cupules at KR1 showing Alan Watchman removing crust samples.

sequences for a layered crust should indicate slow progressive deposition of components in cupules that are unaffected by contamination. Signs of contamination by young or old components should be clearly evident by a wide difference in ages between layers. Furthermore, the thickness of a crust compared with its age should indicate whether deposition in crusts was uniform or if erosion had occurred (see the Appendix for details of the extraction technique).

\section{Results}

\section{Mineralogical analysis}

The rock type on which crusts have formed is a mediumgrained quartz sandstone cemented with a kaolinite matrix at Granilpi (KR10) and Jinmium (KR24) and by secondary silica and clay at the second Jinmium site (KR1). The crusts covering cupules are thin, ranging from $0.1 \mathrm{~mm}$ to $0.25 \mathrm{~mm}$ thick; they are compositionally and texturally stratified.

The KR1 crust is essentially composed of a single calcium-rich deposit of oxalate with interdigitated small lenses of sulphate (mainly gypsum), fine clay lamellae and minute quartz grains (Figure 2). The Granilpi KR10 crust contains a basal silty deposit overlying a thin dis- 


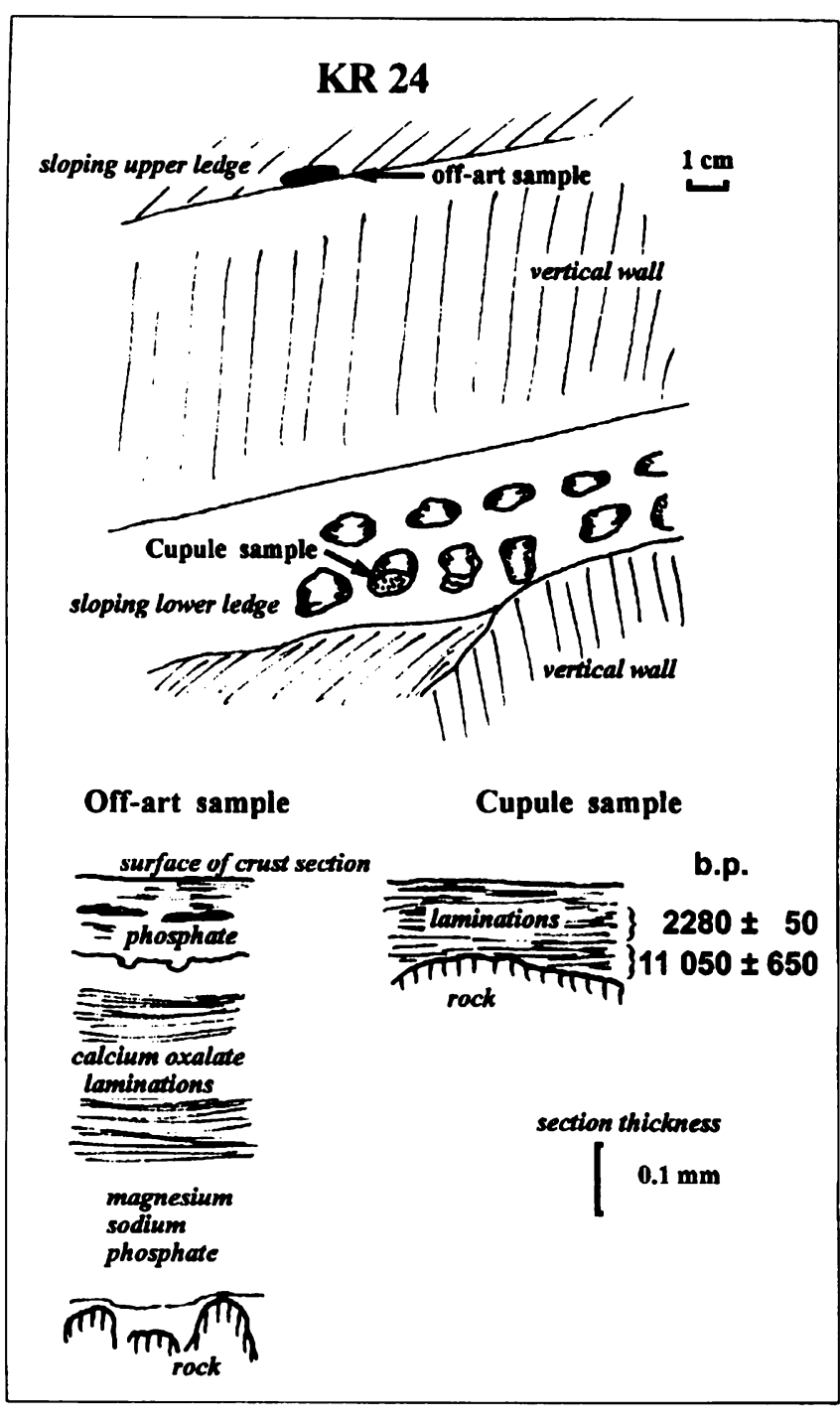

Figure 4. Sketches of the excavated area of crust and enlarged cross sections through the laminated crusts offart and within a cupule at KR24. Age determinations are shown in uncalibrated radiocarbon years bp.

contimuous band of hematite and jarosite covering the quartz grains of the underlying rock. The upper half of the KR 10 crust appears relatively homogeneous, consisting of finely laminated clay and a mixture of fine quartz particles, whewellite $\left(\mathrm{CaC}_{2} \mathrm{O}_{4} \cdot \mathrm{H}_{2} \mathrm{O}\right)$, gypsum $\left(\mathrm{CaSO}_{4} \cdot 2 \mathrm{H}_{2} \mathrm{O}\right)$ and magnesium phosphate. An off-art sample of crust collected from the broken edge of the engraved ledge, though thicker than in the cupule, essentially consists of the same mineralogical composition (Figure 5). Analysis of the crust at site KR24 is based on a sample taken from an 'off-art' location, a partly detached flake about $10 \mathrm{~cm}$ away from the cupule selected for dating; the crust in the cupule itself was too thin and fragile for cross-sectioning and mineralogical study. The KR24 off-art crust is between 0.5 and 0.75 $\mathrm{mm}$ thick, compared with only about $0.1 \mathrm{~mm}$ in the

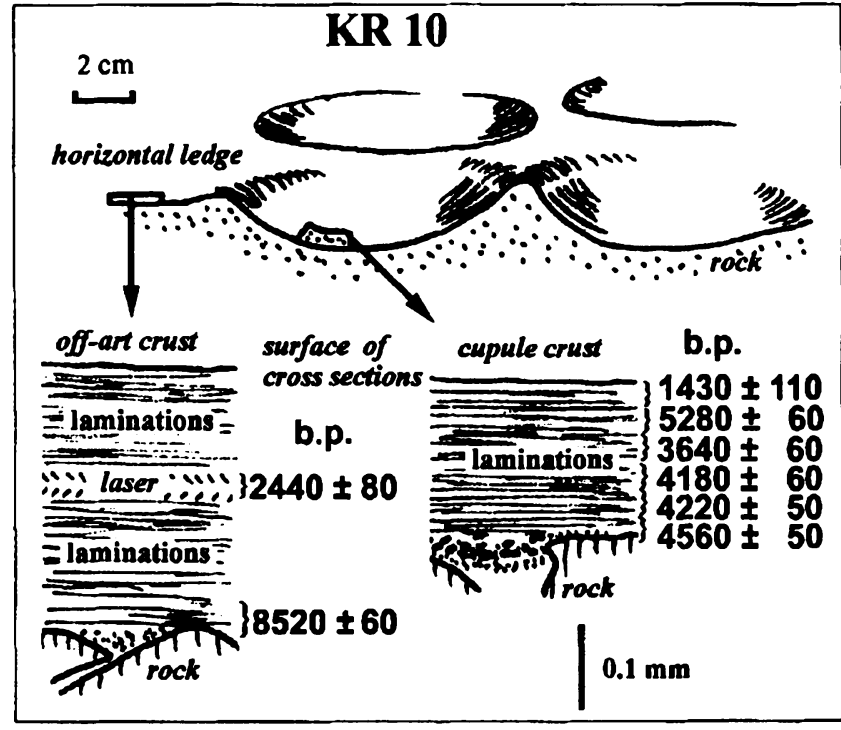

Figure 5. Sketches of the excavated area of crust and enlarged cross sections through the laminated crusts offart and in the horizontal cupule at KR10. The sequence of uncalibrated radiocarbon age determinations (years bp) are indicated for the respective depths within the crust. A focused laser was used to extract carbon from the centre of the relatively thick off-art section of crust.

cupule (Figure 4). Four distinct layers in the KR24 off-art crust are composed of variable amounts of calcium, magnesium and sodium phosphate, as well as oxalate salts. Quartz and clay are disseminated through the crust, not confined to a single layer. The basal layer essentially comprises sodium-magnesium phosphate, the layer above that contains mainly whewellite, the third layer consists of alternating oxalate and phosphate bands and the surface layer is predominantly magnesium phosphate.

\section{AMS determinations}

Sixteen age estimates for oxalate in micro-excavated layers range from 1,430 to 11,050 radiocarbon years before present (bp; Table 1). Because the age of oxalate at the base of a crust covering a cupule gives an estimate of its minimum age the Jinmium-Granilpi cupules are at least $2,130 \pm 60$ radiocarbon years old at KR1, 11,050 \pm 650 (but see below) at KR24 and 4,560 \pm 50 at KR10.

Three measurements of $\delta^{13} \mathrm{C}$ were also made to support the proposition that the carbon in oxalate is derived from micro-organic activity. An essential requirement of the dating strategy is to show that the age determinations for carbon atoms in the oxalate salt represents the age of formation of oxalic acid by micro-organisms on the surface of a cupule. The measured $\delta^{13} \mathrm{C}$ for oxalate in excavated layers of crust ranged from -14.9 per mil (Layer 2 of KR10) to -17.2 per mil (layer 4 at KR1). Layer 2 in KR1 gave a $\delta^{13} \mathrm{C}$ measurement of -15.7 per mil. Similar 


\begin{tabular}{|c|c|c|c|c|c|}
\hline Layer & AMS Lab. \# & $\begin{array}{l}\text { Crust } \\
\text { (mg) }\end{array}$ & Fraction Modern & $\begin{array}{l}\delta^{13} \mathrm{C} \\
\text { (per mil) }\end{array}$ & $\begin{array}{l}\text { Age } \\
\text { (years bp) }\end{array}$ \\
\hline \multicolumn{6}{|c|}{ Granilpi KR10 crust ( $0.2 \mathrm{~mm}$ thick) } \\
\hline Top surface & CAMS 42877 & 6.70 & $0.8415 \pm 0.0111$ & -17.0 & $1,430 \pm 110$ \\
\hline Layer 1 & CAMS 42878 & 17.74 & $0.5211 \pm 0.0033$ & “ & $5,280 \pm 60$ \\
\hline Layer 2 & CAMS 45669 & 18.46 & $0.6425 \pm 0.0042$ & -15.0 & $3,640 \pm 60$ \\
\hline Layer 3 & CAMS 44351 & 19.02 & $0.5976 \pm 0.0039$ & -17.0 & $4,180 \pm 60$ \\
\hline Layer 4 & CAMS 44348 & 17.64 & $0.5941 \pm 0.0036$ & “ & $4,220 \pm 50$ \\
\hline Layer 5 base & CAMS 44349 & 24.31 & $0.5695 \pm 0.0035$ & “ & $4,560 \pm 50$ \\
\hline Off-art mid & CAMS 45672 & laser & $0.7477 \pm 0.0066$ & “ & $2,400 \pm 80$ \\
\hline Off-art base & CAMS 45670 & 12.86 & $0.3402 \pm 0.0025$ & “ & $8,520 \pm 60$ \\
\hline \multicolumn{6}{|c|}{ Jinmium KR 1 crust $(0.25 \mathrm{~mm}$ thick) } \\
\hline \multicolumn{6}{|c|}{ Top surface undated } \\
\hline Layer 1 & OxA-7368 & 29.52 & n.a. & -26.0 & $3,525 \pm 55$ \\
\hline Layer 2 & CAMS 45666 & 17.84 & $0.8403 \pm 0.0052$ & -15.7 & $1,470 \pm 50$ \\
\hline Layer 3 & OxA-7369 & 45.17 & n.a. & -26.0 & $5,840 \pm 65$ \\
\hline Layer 4 & CAMS 45667 & 18.77 & $0.7502 \pm 0.0048$ & -17.2 & $2,370 \pm 60$ \\
\hline *Dichromate & CAMS 45668 & 18.77 & $0.7643 \pm 0.0235$ & -17.0 & $2,220 \pm 250$ \\
\hline Layer 5 & CAMS 44350 & 15.13 & $0.7713 \pm 0.0050$ & “ & $2,130 \pm 60$ \\
\hline \multicolumn{6}{|c|}{ Jinmium KR24 crust ( $0.1 \mathrm{~mm}$ thick) } \\
\hline Top surface & CAMS 42879 & 6.27 & $0.7566 \pm 0.0046$ & “ & $2,280 \pm 50$ \\
\hline Layer 1 & OxA-7367 & 32.15 & n.a. & -26.0 & $11,050 \pm 650$ \\
\hline
\end{tabular}

Table 1. Accelerator mass spectrometry radiocarbon determinations (uncalibrated) for the age of oxalate carbon in laminated rock surface crusts covering cupules, Jinmium- Granilpi area, Northern Territory (CAMS = Center for AMS, Lawrence Livermore National Laboratory, USA; OxA = Oxford University Accelerator Unit, UK; Crust = weight of powder collected from micro-excavation; $\delta 13 \mathrm{C}$ was measured on samples where sufficient gas was available; $*=$ dichromate treatment of solution after permanganate oxidation; n.a. = not available).

analyses were made of modern oxalic acid (-18.2 per mil) and calcium oxalate formed as a precipitate in the reaction of the acid with calcium chloride ( -19.8 per mil) solution at $60^{\circ} \mathrm{C}$. The measurements for natural samples are consistent with values for synthetic oxalate compounds and those expected for metabolic products derived from Krebs cycle photosynthesis (Hedges et al. 1998).

Two off-art age estimates for oxalate indicate that crust started to form on the ledge in shelter KR10 approximately 8,520 years ago (CAMS 45670). Crust then continued to form until the recent past as evidenced by the measurement mid way up the layered off-art crust sequence $(2,400 \pm 80$ years bp, CAMS 45672$)$.

\section{Discussion}

The use of micro-excavation techniques and selective extraction of carbon from oxalate salts in crusts covering cupules has given us the opportunity, for the first time, to look in detail at the archaeology of cupules. Our observations and analyses provide data which we believe will stimulate debate about rock-art dating methods and their reliability and the use of radiocarbon dates from crusts to indicate minimum ages for engravings. We discuss these issues below and consider their implications for environmental changes, human occupation of rock shelters and rock-art chronologies in northern Australia.

\section{Reliability of age estimates}

Are all or only some of the radiocarbon age determinations, using oxalate in the crusts, reliable indicators of cupule age? Calcium oxalate salts are highly insoluble; once formed, they are extremely difficult to redissolve in water and transport to another site, so they are considered excellent sources of datable carbon. Oxalate salts are also believed to form from the activities of microorganisms that live on damp, dusty rock faces, with the carbon being derived from the atmosphere at the time. Therefore, the micro-excavated layers are most likely to contain oxalate salts that have crystallised there in their primary place of deposition. It is also because of this chemical stability that the oxalate salts do not exchange 
carbon with the environment once the carbon has been locked into the crystalline phase. Measuring the age of carbon in oxalate is therefore a sound way of determining when the oxalate was deposited.

Introduction of carbon-bearing substances (humic acids, charcoal, carbonate, plant and insect debris, pollen etc.), to materials that form rock surface crusts will not affect the age determinations for oxalate because they will not be oxidised under the rapid and mild reaction conditions specifically chosen in this case. The acidified permanganate reaction was used for the JinmiumGranilpi samples because it decomposes oxalate minerals in a few minutes (Gillespie 1997). Much stronger oxidising conditions and longer reaction times are necessary to decompose other organic substances (Bird and Gröcke 1997). Potassium dichromate was used on the permanganate-reactant solution to oxidise the organic matter, but only one sample (KR1 Layer 4) produced enough carbon dioxide for radiocarbon assay. The age determination for that extraction overlaps the age of the oxalate carbon (one sigma), suggesting that both the organic matter and the oxalate salt were deposited simultaneously.

The warm acid pre-treatment and use of the permanganate oxidation reaction should have minimised contamination from non-oxalate carbon sources, but the problem of contamination from old carbon from carbonate cannot be overlooked. While the mineralogical analyses did not identify calcite, dolomite or any other carbonate mineral, a small, undetectable amount of carbonate could have been present in the powders. In warm acidic solutions, dolomite reacts much more slowly than calcite producing carbon dioxide. If dolomite was present in the crusts in quantities less than the detection limit of X-ray diffractometry, then old carbon was probably mixed with carbon from oxalate making the estimate of age older than the real value.

Each radiocarbon age determination is actually the pooled mean age of all the oxalate crystals in a sample because the micro-excavated powder contains oxalate that was deposited across a surface area of several square centimetres. As oxalate crystals were deposited in space, as well as over time, across the surface of a cupule the AMS ${ }^{14} \mathrm{C}$ age estimate derives from the mean carbon-14 activity of all crystals in a sample. Some crystals will be older than others, but the pooled mean age will indicate approximately when all the crystals in that layer were deposited. In addition, and because of slight undulations within a layer, the pooled mean age of oxalate crystals in one layer may be slightly older than the layer immediately underneath. Sampling irregularities will also increase the likelihood that an older layer will be superimposed over a younger layer (e.g. Figure 4), especially where the depositional layers have been laid down in a complex way (Figure 2).

The sequence of determinations in the KR10 crust demonstrates that the pooled mean age of oxalate in a series of layers becomes progressively younger towards the surface. This is expected and indicates highly reliable measurements. Slightly less confidence is provided by the determinations in KR1, but the textural evidence and micro-site setting of that sample substantiate the interpretation that structural weakness has permitted the introduction of younger oxalate-bearing sediment into fractured crust.

The crust at KR24 is thin, less than half that at KR10 and KR1, but it is considerably older. The great difference in age between the onset of crust formation in these crusts could be caused by the initial accumulation in the KR24 cupule of older components derived from the physical weathering of crust on the sloping ledge above the cupule. On the other hand, it could also signal the possibility that some other chemical process may have taken place during oxidation of the oxalate salts in that sample. Mass fractionation of carbon isotopes may have occurred in such a way that ${ }^{14} \mathrm{C}$-deficient carbon dioxide was liberated from the oxalate salts. This would give an apparently older age because the mean ${ }^{14} \mathrm{C}$ activity of the gas would be lower than in the salt. Further work needs to be done to investigate whether certain minerals can affect the oxidation of oxalate salts. The oxalate in the surface layer of crust in cupule KR24 is consistent with age estimates for similar surfaces at the other two sites, so this potential problem may not be widespread. It therefore seems more likely that contamination of the basal oxalate in KR24 with older substances derived from physical erosion of existing crust on the ledge higher upslope could have shifted the measured age to an older value.

\section{Minimum ages for Keep River cupules}

Radiocarbon age estimates for carbon in oxalate in the sample of three Jinmium-Granilpi cupules give the cupules a mid-Holocene minimum age. The pecked cupule at KR 1 is at least 2,130 years old and possibly more than 5,840 years old. This minimum age estimate is consistent with the optical and elemental carbon chronology (Roberts et al. 1998) of sediments that cover a fallen slab of sandstone containing pecked cupules that was retrieved from an excavation beneath the engraved panel. Optically stimulated luminescence measurements on single quartz grains and radiocarbon dating of finely dispersed charcoal indicate that sediments covering the fallen slab are about 3,000 years old (Roberts et al. 1998). If this age estimate of the sediment is correct, then the minimum age of 5,840 years for the cupule on the shelter wall is a reasonable estimate for when the cupule might have been last used.

At the KR10 site the minimum age of the cupule is at least 4,560 years, but it could also be more than 5,280 years old. This matches the mid-Holocene age at KR1, and agrees with the thickness and age estimate for a sample of crust collected from an off-art position at the same site (Figure 5). The age determination of 8,520 years for off-art crust may mark the beginning of formation of the rock crust on that ledge. 
At KR24, the minimum age estimate of $11,050 \pm 650$ years bp for the cupule is more problematic because a disparity is apparent between the thickness of the crust and its age when compared with the other crusts in the Keep River region. A mid-Holocene age would not be implausible for the base of the crust in this cupule, but the measured age seems far too old. More radiocarbon analyses of crust in other cupules and from off-art locations plus with additional chemical analyses and research into oxidation reactions involving oxalate salts should explain the apparent anomalous result.

The KR10 cupule has a thin hematite deposit at the interface between the base of the crust and the underlying sandstone. If this is remnant ochre, as we suspect, then it has implications not only for cupule function, but also in terms of oxalate and crust accumulation. If the cupule were used for grinding ochre, then this physical activity would have prevented oxalate and crust formation. While an age of 4,560 radiocarbon years was obtained for oxalate at the base of the crust in the KR10 cupule, this represents the approximate mid-Holocene period when cupule use ceased and crust started to form.

The KR10 cupule is certainly older than the measured age of oxalate at the base of the crust that lines its base and sides. One can argue that all evidence of crust formation prior to the presumed start of crust formation on the ledge $(8,520$ years ago), has been removed during grinding of materials and that the cupule is more than 8,520 years old. While it is not possible to specify the start of cupule production using these radiocarbon age estimates it is clear that the sandstone underlying the cupules was not exposed after the mid-Holocene. Therefore the cupules were presumably not repecked or used for their original function after that time.

\section{Implications for palaeoenvironmental studies}

Mid-Holocene ages for crust in Keep River cupules are consistent with crust thicknesses and ages determined elsewhere in northern Australia (Watchman and Campbell 1996; Watchman 1997). Such relatively recent age estimates for crust formation in the Keep River, Kimberley and Victoria River districts (Watchman et al. submitted), might also signal that environmental conditions in northern Australia changed during the midHolocene to warmer and wetter conditions, favouring micro-organic colonisation of rock shelters and the consequent production of oxalate salts.

Palaeoecological evidence for northern Australia, albeit derived mostly from coastal and north-east Queensland upland sites about $1700 \mathrm{~km}$ from Keep River, indicates warmer and wetter conditions during the early-mid Holocene (Hiscock and Kershaw 1992). Differences between this period and the late Pleistocene are likely to have been extreme in the Keep River and surrounding region. While detailed research is still in progress, it is expected that greater continentality of climate, characteristic of the whole of northern Australia around the last glacial maximum (Woodroffe 1993) would have been exacerbated in all those rivers draining onto the extensive north west shelf, now the Joseph Bonaparte Gulf. Swamps in the Great Sandy Desert began to accumulate about 7000 years ago due to an inferred increase in regional precipitation, with stable vegetation prevailing since then (Wyrwoll et al. 1986). If crust formation requires warm and wet conditions, we would not expect to see any evidence until well into the Holocene (McGlone et al. 1992).

The picture is complicated somewhat at both ends of the time scale. Recent research shows that temperature and precipitation fluctuations within the glacial-interglacial cycles are not always in phase (Nanson et al. 1992, Kershaw and Nanson 1993). There is now evidence from both northern (Nott 1996) and southern Australia (Page et al. 1994) of wetter events and maintenance of high lake levels, possibly associated with reduced evaporation, across the glacial maximum. Whether such cool and wet conditions were potentially conducive to microorganic colonisation is not yet known.

Evidence of climatic change is likely to provide the opportunity to better understand the conditions under which the crusts were formed. However, the available evidence indicates both spatial and temporal variability. In reviewing a range of evidence, McGlone et al. (1992) argued that the last 3-5000 years saw drier and more variable conditions with high ENSO (El Niño Southern Oscillation) activity. Short periods of decreased wet season rainfall contributed to episodic dune initiation across north-western Australia, particularly between 2700 and 1800 years ago (Lees et al. 1992). On the other hand, the onset of organic deposition at a number of Cape York swamp sites about $2500 \mathrm{bp}$ is interpreted as evidence of more reliable water levels, or at least less severe dry seasons, than previously (Stephens and Head 1995). The most precise estimates of past seasonality come from the work of Kershaw and Nix (1988) who estimated precipitation of the driest quarter. Swamp accumulation and maintenance is consistent with their interpretation of a slight increase in driest quarter precipitation at Lake Euramoo, on the Atherton Tableland, between 3600 and $2600 \mathrm{bp}$. The site specific, seasonal or longer term influences on crust formation remain to be clarified by future research. Conversely, if they can be clarified, the crusts themselves will provide a new line of palaeoecological evidence.

\section{Implications for rock-art sequences}

Direct dating of the Jinmium-Granilpi cupule crusts in this study is consistent with at least three scenarios:

a) Early age estimate for both the deposit and the art (exceeding 45,000 years),

b) Recent age estimate for both the deposit and the cupule art (less than 10,000 years), and

c) Middle age estimate of Pleistocene age for either or both (up to 45,000 years). 
a) Early

The rock-art sequence in the Jinmium-Granilpi area and its comparison with other rock-art sites across northern Australia suggests a maximum age of cupules of many tens of thousands of years (Taçon et al.1997). Support for ancient cupules was initially provided by preliminary thermoluminescence determinations of Jinmium deposits of more than 58,000 years (Fullagar et al. 1996). However, recent age determinations using OSL and elemental carbon for Jinmium deposits (Roberts et al. 1998) do not support early cupule production. There is also a general lack of direct evidence of human art activity or habitation for this period from other locations within northern Australia. The exceptional case is the rare discovery of striated ochre in the occupation deposit at Malakunanja dated to about 60,000 years ago (Roberts et al. 1990; but also see O'Connell and Allen 1998). As well, radiocarbon and cation-ratio age determinations of over 40,000 years for South Australian rock engravings have recently been withdrawn (Dorn 1997), so there is only slim evidence for early production of cupules in the far north.

\section{b) Recent}

A very recent or Holocene age for cupule engravings does not sit well with the results of rock-art research at cupule sites across northern Australia, although all researchers do note that cupules, like hand stencils, were made during many time periods, including during the ethnographic present (eg. Flood 1996:29). General agreement exists that large wall panels of cupules (as found at Jinmium and Granilpi) are consistently found under other forms of painted, engraved or beeswax motifs (Chaloupka 1993; Flood 1996; Taçon and Chippindale 1994; Taçon et al. 1997; Walsh 1994; Welch 1993). Many of these later motifs are considered to have Pleistocene age, such as the Dynamic Figures and Large Naturalistic Animals of Arnhem Land or the Bradshaw Figures and Irregular Infill Animals of the Kimberley.

If the recent scenario for large wall panels of cupules were correct, then all north Australian rock-art chronologies from Arnhem Land to the Pilbara would have to be significantly revised, with age estimates for all periods re-evaluated and associations between rock-art and deposits reassessed. It seems to us highly likely that some cupules in northern Australia were made much earlier than $4500-5800$ years ago.

\section{c) Middle}

At Carpenter's Gap, 500 km southwest of Jinmium, in the Kimberley, O'Connor (1995) has excavated a ceiling rock slab bearing ochre from the floor deposit radiocarbon dated to 39,000 years, and argues it is from a painting. Wandjina style and distinct paintings of the type consistently found over cupules by Walsh (1994), Welch
(1993) and others occur in the same shelter above the excavated floor. Also in the Kimberley, OSL age determinations obtained from a mud-wasp nest that is associated with a painted human figure suggest a minimum age of 17,000 - 26,000 years for weathered purple paintings. In contrast, Watchman et al. (1997) have obtained AMS radiocarbon determinations suggesting some Bradshaw paintings are probably only 4000 years old, or marginally older. It has been demonstrated through superimposition studies that all of these forms (including a Bradshaw Figure in the Granilpi complex), post-date many cupules in both the West and East Kimberley regions (Taçon et al. 1994; Walsh 1994). Although the OSL mud-wasp dates cannot be accepted unequivocally they do suggest that some paintings and cupules are Pleistocene in age. A gap of only 500 years between cupule production and Bradshaw painting production raises questions about the relative sequence of rock-art styles in the region. Watchman's AMS determinations on Bradshaw paintings thus support our contention that the minimum ages of 4500 years obtained from crusts on top of cupules do not indicate maximum limits for cupule production and that some cupule ages could be substantially older. Finally, archaeological excavations at a number of Kimberley sites have noted a long cultural hiatus between about 19,000-20,000 years ago and 8000-3000 years ago (O'Connor 1990: 367; Morwood 1998; Morwood and Hobbs 1998). If the Jinmium sediments conform to this pattern, then it is likely the cupules were either made prior to 19,000 years ago or in the Holocene and that many of the paintings were applied after the cupules during site re-occupation.

\section{Conclusions}

A significant achievement of this project is the dating of oxalate-carbon in thin layers, only $0.25 \mathrm{~mm}$ thick, using extremely small samples obtained from micro-excavations of rock surface crusts. While there is some variability in radiocarbon ages through crustal layers the determinations provide reliable age estimates for the timing of oxalate deposition. The measurements also show, at the nanometer scale, the relatively uniform deposition of oxalate across small areas of crust, despite the presence of slight undulations. Formation of oxalate in crusts occurs through time and space with deposition in a cupule being controlled by environmental factors and surface conditions across short distances. The range of radiocarbon determinations for carbon associated with oxalate minerals deposited in thin crusts over cupules and rock ledges obtained at these sites in the Jinmium-Granilpi area highlights the potentially complex histories and processes leading to crust formation. The minimum age of a cupule can be estimated after assessing the chronological integrity and the internal and external consistency of the age estimates and by observing the extent to which textural and structural features contribute to disrupting stratigraphic and age relationships within the overlying crust. 


\section{Acknowledgements}

Recording of rock-art and collection of dating samples were undertaken from 8/6/97-19/6/97 by Watchman, Fullagar and Taçon. We thank Paddy Carlton, Waringarri Aboriginal Corporation, and the Marralam Aboriginal Community, particularly Biddy Simon, Morris Simon and Polly Wandanga.

Ingrid Ward provided X-ray micro-diffraction and scanning electron microprobe analyses with assistance from Dr Chris Cuff and Bob Riel, Advanced Analytical Centre, James Cook University. Laboratory equipment for selective oxidation of oxalate was purchased through a large ARC grant (A39531774) to Dr John Campbell and Dr Alan Watchman, and Watchman's research is supported by an ARC postdoctoral fellowship (F3970686). Dr John Southon, Lawrence Livermore National Laboratory and Dr Robert Hedges, Oxford University Accelerator Unit, expedited the radiocarbon determinations.

The Australian Museum provided funding and support with a grant through its People and Place Research Centre. Fullagar was funded by an ARC Research Fellowship. Jim Specht, Christopher Chippindale, Sven Ouzman, Richard Gillespie and an anonymous reviewer are thanked for comments that improved this manuscript.

\section{References}

Bednarik, R.G. 1996. The cupules on Chief's Rock, Auditorium Cave, Bhimbetka. Artefact 19:63-72.

Bird, M.I. and D.R. Gröcke 1997. Determination of the abundance and carbon isotope composition of elemental carbon in sediments. Geochimica et Cosmochimica Acta 61:3413-3423.

Chaloupka, G. 1993. Journey in Time. Reed Books, Sydney.

$\rightarrow$ Dorn, R. 1997. Uncertainties in the 14C ages for petroglyphs from the Olary province, South Australia. Archaeology in Oceania 32(3):214-15.

Flood, J. 1996. Culture in early Australia. Cambridge Archaeological Journal 6(1):3-36.

Flood, J. 1997. Rock Art of the Dreamtime: images of ancient Australia. Angus \& Robertson, Sydney.

Fullagar, R.L.K., D.M Price and L.M. Head 1996. Early human occupation of northern Australia: archaeology and thermoluminescence dating of Jinmium rock-shelter, Northern Territory. Antiquity 70:751-773.

Gillespie, R. 1997. On human blood, rock art and calcium oxalate: further studies on organic carbon content and radiocarbon age of materials relating to Australian rock art. Antiquity 71:430-437.

Hedges, R.E.M., C.B. Ramsey, G.J. Van Klinken, P.B. Pettitt, C. Nielsen-Marsh, A. Etchegoyen, F. Niello, M.T. Boschin and A.M. Llamazares 1998. Methodological issues in the ${ }^{14} \mathrm{C}$ dating of rock paintings. Radiocarbon 40 (1):35-44.

Hiscock, P. and A.P. Kershaw 1992. Palaeoenvironments and prehistory of Australia's tropical Top End. In J.R. Dodson (ed.) The Naïve Lands. Prehistory and environmental change in Australia and the Southwest Pacific, pp. 43-75, Longman Cheshire, Melbourne.
Kershaw, A.P. and G.C. Nanson 1993. The last full glacial cycle in the Australian region. Global and Planetary Change 7:1-9

$\rightarrow$ Kershaw, A.P. and H.A. Nix 1988. Quantitative palaeoclimatic estimates from pollen data using bioclimatic profiles of extant taxa. Journal of Biogeography 15:589-602

Lees, B.G., Y. Lu and D.M. Price 1992. Thermoluminescence dating of dunes at Cape St Lambert, East Kimberleys, northwestern Australia. Marine Geology 106:131-139

McGlone, M.S., A.P. Kershaw and V. Markgraf 1992. El Niño/Southern Oscillation climatic variability in Australasian and south American paleoenvironmental records. In H.F. Diaz and V. Markgraf (eds) El Niño. Historical and paleoclimatic aspects of the Southern Oscillation, pp. 435-462. Cambridge, Cambridge University Press,

Morwood, M.J. 1998. The archaeology of Kimberley art. Paper presented at the 1998 AURA Inter-Congress in Canberra, ACT on 7 February 1998.

Morwood, M.J. and D.R. Hobbs 1998. The archaeology of Kimberley art. In G.L. Walsh (ed.), Bradshaw art of the Kimberley. Nowan kas Publications, Takarakka Rock Art Research Centre.

Nanson, G.C., D.M Price and S.A. Short 1992 Wetting and drying of Australia over the past 300ka. Geology 20:791-794.

Nelson, D.E., G. Chaloupka, C. Chippindale, M.S. Alderson and J.R. Southon 1995. Radiocarbon dates for beeswax figures in the prehistoric rock art of northern Australia. Archaeometry 37(1):151-56.

Nott, J. 1996. Late Pleistocene and Holocene sea-level highstands in northern Australia. Journal of Coastal Research 12(4):907-910.

O'Connell, J. and J. Allen 1998. When did humans first arrive in greater Australia and why is it important to know? Evolutionary Anthropology 6:132-46.

O'Connor, S. 1990. 30,000 years in the Kimberley: a prehistory of the islands of the Buccaneer Archipelago and adjacent mainland, west Kimberley, western Australia. Unpublished PhD thesis, University of Western Australia, Perth.

O'Connor, S. 1995. Carpenter's Gap Rockshelter 1:40,000 years of Aboriginal occupation in the Napier Ranges, Kimberley, WA. Australian Archaeology 40:58-9.

Page, K., A. Dare-Edwards, G. Nanson, and D. Price 1994. Late Quaternary evolution of Lake Urana, New South Wales, Australia. Journal of Quaternary Science 9:47-57.

Price, D. 1998a. Monday viewpoint: dating the past from 100,000 to 10,000 years. The Sydney Morning Herald. June $1, \mathrm{p} 19$.

Price, D. 1998b. Thermoluminescence dating in Australia: from Mungo to Jinmium and back. Unpublished paper presented to Australia and New Zealand Geomorphology Group conference, Goolwa. Abstracts $8^{\text {th }}$ Biennial. P. 45.

Roberts, R. 1998. Monday viewpoint: dating the past from 100,000 to 10,000 years. The Sydney Morning Herald. June 1, p. 19.

Roberts, R.G., R. Jones and M.A. Smith 1990. Thermoluminescence dating of a 50,000 year-old human occupation site in northern Australia. Nature 345:153-156.

Roberts, R., G. Walsh, A. Murray, J. Olley, R. Jones, M. Morwood, C. Tuniz, E. Lawson, M. McPhail, D. Bowdery and I. Naumann 1997. Luminescence dating of rock art and past environments using mud wasp nests in northern Australia. Nature 387:696-699. 
Roberts, R., M. Bird, J. Olley, R. Galbraith, E. Lawson, G. Haslett, H. Yoshida, R. Jones, R. Fullagar, G. Jacobsen and Q. Hua 1998. Optical and radiocarbon dating at Jinmium rock shelter, northern Australia. Nature 393:358-362.

Rosenfeld, A. and C. Smith 1997. Recent developments in radiocarbon and stylistic methods of dating rock-art. Antiquity 71:405-411.

Spooner, N. 1998. Human occupation at Jinmium, northern Australia: 116,000 years ago or much less? Antiquity 72:173-178.

Stephens, K. and L. Head 1995. Palaeoecology of archaeological and swamp sites in S.E. Cape York Peninsula. In M.J. Morwood and D. Hobbs (eds) Quinkan Prehistory: the Archaeology of Aboriginal Art in S.E. Cape York Peninsula, pp. 18-32. Tempus 3, Anthropology Museum, University of Queensland.

Taçon, P.S.C. 1998. Tracking time: a human concern. ABC Science: The Lab, 8 April, http://www.abc.net.au/science/slab/tacon/story.htm.

Taçon, P.S.C. and C. Chippindale 1994. Australia's ancient warriors: changing depictions of fighting in the rock art of Arnhem Land, N.T. Cambridge Archaeological Journal 4(2):211-248.

Taçon, P.S.C., R. Fullagar, S. Ouzman and K. Mulvaney 1997. Cupule engravings from Jinmium-Granilpi (northern Australia) and beyond: exploration of a widespread and enigmatic class of rock markings. Antiquity 71:942-965.

Walsh, G. 1994. Bradshaws: ancient rock paintings of Australia. Edition Limitée, Geneva.

Watchman, A. 1993. Evidence of a 25,000-year-old pictograph in northern Australia. Geoarchaeology 8(6):465-473.

Watchman, A. 1997. Dating the Kimberley rock paintings. In K.F. Kenneally, M.R. Lewis, M. Donaldson, and C. Clement (eds), Aboriginal Rock Art of the Kimberley, pp. 39-46. Occasional Paper No.1 Kimberley Society, Perth, Western Australia.

Watchman, A. and J. Campbell 1996. Micro-stratigraphic analyses of laminated oxalate crusts in northern Australia. In M. Realini, and L. Toniolo (eds) The oxalate films in the conservation of works of art. pp. 408-422. Editeam, Bologna.

Watchman, A.L., B. David and I. McNiven submitted. Microarchaeology of engraved and painted rock surface crusts at Yiwarlarlay (The Lightning Brothers site), Northern Territory, Australia. Journal of Archaeological Science.

Watchman, A. and E. Hatte 1996. A nano approach to the study of rock art in 'The Walkunders', Chillagoe, North Queensland, Australia. Rock Art Research 13:85-92.

Watchman, A.L., G.L. Walsh, M.J. Morwood and C. Tuniz 1997. AMS radiocarbon dating age estimates for early rock paintings in the Kimberley, N.W. Australia: preliminary results. Rock Art Research 14:18-26.
Welch, D. 1993. Early 'naturalistic' human figures in the Kimberley, Australia. Rock Art Research 10:24-37.

Woodroffe, C.D. 1993. Late Quaternary evolution of coastal and lowland riverine plains of Southeast Asia and northern Australia: an overview. Sedimentary Geology 83:163-175

Wyrwoll, K.H., N.L. McKenzie, B.J. Pederson and I.J. Tapley 1986. The Great Sandy Desert of northwestern Australia: the last 7000 years. Search 7:208-210.

\section{Appendix}

Geochemical facilities at the Advanced Analytical Centre, James Cook University were used to identify the minerals in the crusts. A Siemens General Area Detector Diffraction System (GADDS) was used for X-ray diffractometry and a JEOL JXA-840A scanning electron microprobe for mapping major element distributions and for obtaining line scans across polished resin-impregnated blocks of rock surface chips.

The extraction of oxalate carbon from rock surface crusts covering cupules for AMS ${ }^{14} \mathrm{C}$ dating followed the method described by Gillespie (1997). An acidified solution of powdered crust heated to $50^{\circ} \mathrm{C}$ was treated with potassium permanganate in an atmosphere of nitrogen $\left(5 \mathrm{M} \mathrm{H}_{2} \mathrm{SO}_{4}\right.$ diluted $1: 10$ by volume; $\left.0.1 \mathrm{M} \mathrm{KMnO}_{4}\right)$ The warm dilute acid reacts with carbonate and evolves carbon dioxide, which was flushed from the system in a stream of nitrogen. Calcium oxalate crystals in the powder are dissolved in the acid forming oxalate ions. After approximately ten minutes, when all carbonate had reacted and the gas lines and reaction vessel had been purged of atmospheric carbon dioxide, a dewar flask containing liquid nitrogen at $-196^{\circ} \mathrm{C}$ was placed under a U-tube outlet from the flask of reactants. Potassium permanganate was injected into the solution to oxidise the oxalate ions to carbon dioxide. This gas condenses in the cold U-tube immersed in liquid nitrogen while the nitrogen passes through. After no further visible signs of reaction between permanganate and oxalic acid solution was evident (excess permanganate is purple) the gas line was closed and evacuated to remove nitrogen. At a vacuum less than $10^{-3}$ torr the vacuum line was shut off and the liquid nitrogen removed from around the U-tube containing condensed carbon dioxide.

Gas pressure in the system was measured when the stainless steel gas line had reached room temperature to ensure that sufficient carbon dioxide gas had been collected for radiocarbon dating. After measuring the pressure of gas it was transferred to a Vycor glass tube sealed at one end. Once the gas had recondensed in the Vycor tube an oxygen-acetylene torch was used to melt and seal the glass tube. This was labelled and shipped to an AMS ${ }^{14} \mathrm{C}$ dating laboratory. Samples were sent to two dating laboratories: Oxford Dating Laboratory, UK and Lawrence Livermore National Laboratory, California, USA. At Oxford the Vycor tube was cracked, the gas dried by condensing water vapour in an alcoholice bath and radiocarbon measurements made directly on the carbon dioxide. At the Lawrence Livermore National Laboratory the glass tubes were cracked, the gas dried and reduced to graphite on finely powdered iron. Graphite targets were pressed into holders and the activity of carbon-14 measured against known standards. 